\title{
Biblia de Alba i facsimile
}

Rabbiner Moses Arragels bibeloversættelse fra hebraisk til spansk

af førstebibliotekar, mag.art. Ulf Haxen

Det kongelige Bibliotek har fra Ny Carlsbergfondet modtaget en fornem boggavei anledning af sit 200 års jubilæum som åbent bibliotek for offentligheden.

Det drejer sig om den spansk jødiske ALBA Bibel (Biblia de Alba), som det engelske forlag, FACSIMILE EDITIONS har ladet reproducere med brug af ekspertisefra kodikologer, bogbindere, forgyldereog edb-teknikerei England, Italien, Spanien og Israel og med anvendelse af avanceret laser teknologi.

Originaleksemplaret af ALBA Bibelen opbevares i Palacio de Liria i Madrid, hos en efterkommer af hertugen af Alba under katalognummer 399. Den omfatter 515 folia (1030 sider) og 334 miniaturer, heraf 6 helsides paneler.

Af årstallet 1422-1433, på ryggen af originalindbindingen, kunne man forledes til at tro, at det tog skriver og illustrator 11 år at fuldende værket. Kilderne antyder imidlertid, at Bibelen var færdigskrevet i 1430, men at det tog yderligere treår for fransiskanermunkenei Toledo at censurere og godkende oversættelsen.

Manden bag det imponerende oversættelses-, kommenterings- og skrivearbejde fra hebraisk til spansk, rabbineren Moses Arragel, var født og opvokset i Guadalajara, nordøst for Madrid, senere bosat i Maqueda, nordvest for Toledo. Her blev oversættelsen til. Miniaturerne derimod er udført af forskellige illuminatorer med hver deres kunstneriske stil og brug af ikonografiske virkemidler.

\section{Et kristent bestillingsværk}

Biblia de Alba var et bestillingsværk. Men ikke udført på opfordring af en jødisk velynder, således som det var almindelig praksis i middelalderen. 


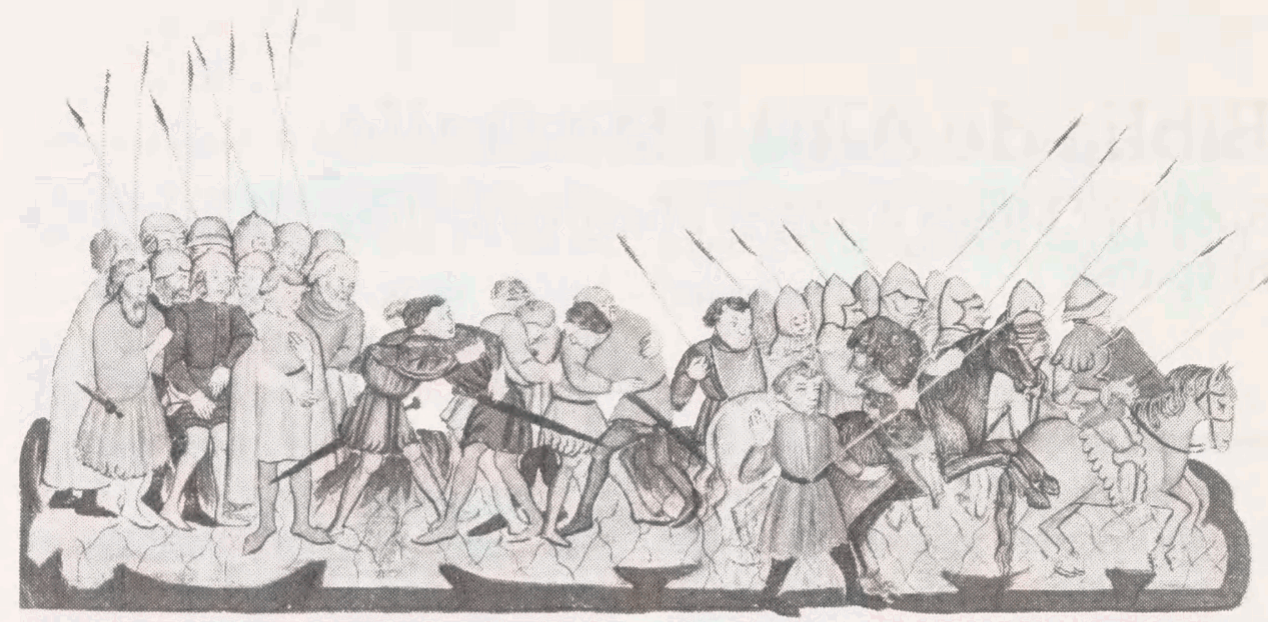

Fol. 213 verso. Slaget mellem Benjamin og Juda stammer (Anden Samuel 2, 12-16). Kong Sauls død (Første Samuel 31).

Kunden var ingen ringere end stormesteren af den katolske Calatrava Orden, Don Luis de Guzmán.

Den katolske stormester ønskede ikke, som man kunne forvente, en oversættelse på grundlag af en kristen fortolkning af "Det Gamle Testamente". Han forlangte udtrykkeligt, at såvel oversættelsen som de ledsagende illustrationer skulle baseres på jødisk tradition og exegese, således som Talmud, Midrash og Kabbala foreskriver.

Moses Arragel undslog sig først af frygt for ubehaglige konsekvenser for ham og hans trosfæller, den spændte politiske situation i Spanien og den omsiggribende inkvisition taget i betragtning.

I 1391 dekreterede kirken den førstesystematiske pogrom mod despanske jøder, hvorefter tvangsdåb og bogbrændinger hørte til dagens orden fra Sevilla i Andalusien til Barcelona i Katalonien.

Fra officiel kirkelig side dekreteredes dogmet om blodets renhed (limpieza de sangre), som fascismen og nazismen senere grundlagde ideologien om racehygiejne og antisemitisme på.

I de sidste hundrede år før den endelige og totale uddrivelse af jøder og arabere i Spanien og Portugal, 1492-1501, kunne end ikke de tvangsdøbte eller 'omvendte' jøder (conversos), der tvungent eller utvungent 'krøb til korset', vide sig sikre, og de offentlige disputationer mellem rabbinere og præster, arrangeret af kirke eller kongehuse udartede til rene skueprocesser, hvor den jødiske sagsfremstilling på forhånd var underkendt. 
I inkvisitionens betændte atmosfære af dobbeltspil og angiveri var Moses Arragels skepsis og nervøsitet over for den stillede opgave ikke ubegrundet.

\section{"Prologen", folio 1 - 25}

Efter drøje forhandlinger opnåede Moses Arragel og de af hans 'trosfæller der endnu var tilbage', som rabbineren polemisk udtrykker det, en acceptabel overenskomst med Don Luis Guzmán, og i april 1422 gik arbejdet i gang, nøjagtigt 70 år før det katolske kongepar, Ferdinand og Isabella, satte punktum for ét kapitel af Spaniens omtumlede historie, og et nyt begyndte med Christopher Columbus' opdagelse af 'Den ny Verden'.

De første 12 folia (24 sider) af Biblia de Alba gengiver minutiøst Moses Arragels forhandlinger med den kristneøvrighed og de politiskeog religiøse overvejelser der udspillede sig mellem forhandlingspartnerne.

Fra fol. 12 til 20 understreges vanskeligheden med at finde den præcise oversættelse til kastiliansk af særligt svære hebraiske ord og begreber. Og for at lette forståelsen for den spanske læser og for de jøder der måtte have glemt at læse hebraisk indsætter Moses Arragel i selve bibelmanuskriptet et nyttigt hjælpe-glossarium.

Som et sikkert tegn på, at denne del af manuskriptet blev indføjet tilsidst, peger den omstændighed, at de sidste fem folia er reserveret Toledofransiskanernes udtalelse og autorisation.

\section{Alba Bibelen, folio 26 - 515}

Under det slidsomme arbejde med oversættelsen og tilsynet af kunstnerne, som for de flestes vedkommende formodes at have været kristne, henholder Moses Arragel sig nøje til den kanoniserede hebraiske Bibel (Tora) og til sin spansk jødiskelandsmand, filosoffen, teologen og lægen Maimonides' (11351204), fortolkning af Bibel og Talmud.

Men i sin oversættelsesmetode var Moses Arragel 'elev' af Toledo skolen, berømt $\mathrm{i}$ hele Europa for sit høje akademiske niveau, udsprunget af de klassiske filologier (græsk, latin, arabisk og hebraisk).

Toledo blev under "Den Vise" Kong Alfonso X (El Sabio) , 1221 - 1284 en blomstrende akademisk og kunstnerisk metropol, hvortil tidens lærde flokkedes fra Europas universiteter. Her blev kimen til den europæiske renæssance og humanismelagt af arabere, jøder og kristne med oversættelser 


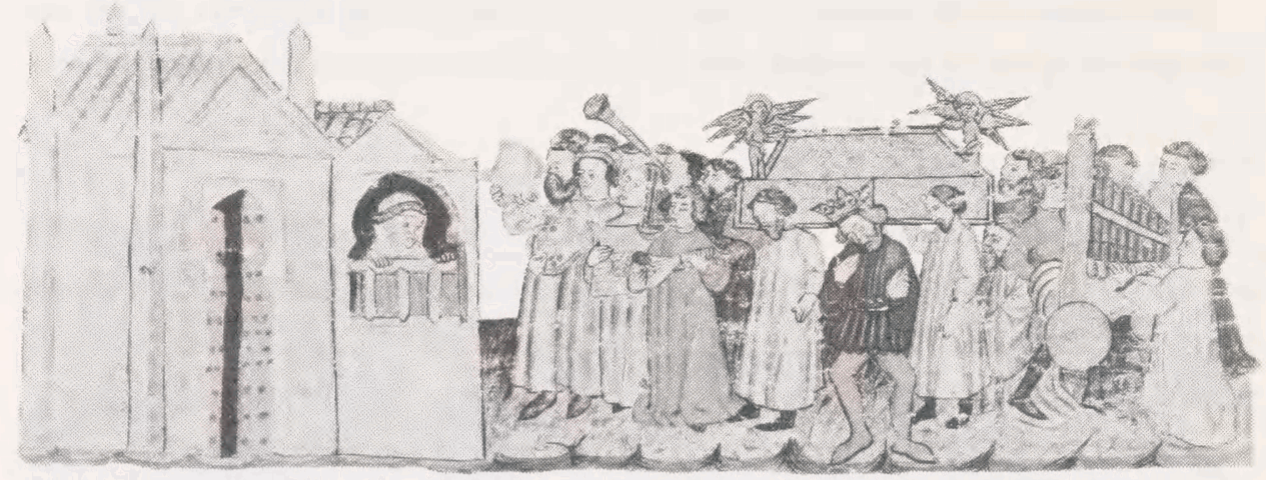

Fol. 216 verso. Kong David danser foran Pagtens Ark (Anden Samuel 6, 14 ff.)

og kommenteringer fra græsk over arabisk til latin af Platon, Aristoteles, Euclid, Galen med mange flere. Araberne havde så tidligt som i 800-tallet indført græsk videnskab til Spanien i arabisk oversættelse og kommentering, fx. gennemal-Farabi's (Alfarabius) berømte forfatterskab. Formidling af græsk viden til latin blev påbegyndt af jøder og kristne allerede efter Toledos generobring af de kristnes styrker i 1085. Araberen Ibn Rushd (Averroës) og jøden Ben Maimon (Maimonides), der begge var influeret af Platons og især Aristoteles' tænkning, blev banebrydende i diskussionen om forholdet mellem tro og fornuft og begge kom de til at påvirke senere kristne skolastikere som dominikaneren Duns Scotus og fransiskaneren Thomas Aquinas.

Men Toledo holdt ikke skansen som intellektuel, kulturel og religiøs højborg for de tre religioner. Den faldt i det endelige holocaust med blodige etniske udrensninger til følge under anførsel af det katolske kongepar Ferdinand og Isabella.

\section{Kolofonen, folio 515v}

Som afslutning på otteårs arbejde med oversættelsen angiver Moses Arragel datoen for fuldførelsen af oversættelsen efter kristen, jødisk og muslimsk tidsregning:

"Denne bibel er oversat til kastiliansk og kommenteret til den sande Herres pris, og til ære for den højærværdige, 'meget katolske', Don Luis de Guzmán, herre og stormester af Calatrava Ordenen. Oversættelsen er fuldført i min hjemby, Maqueda, fredag den 2. juni i året 1430 efter Jesu fødsel, 5190 efter verdens skabelse og i 833 ifølge den muhammedanske kalender".

Den 31. marts 1992, i femhundredåret for uddrivelsen af Spaniens jøder 
blev et eksemplar af facsimileudgaven overrakt Spaniens nuværende regentpar Kong Juan Carlos og Dronning Sophia i Madrids Synagoge, hvor kongen med tilbagekaldelsen af uddrivelsesdekretet af 1492 hilste jøderne velkomne tilbage i Spanien.

Biblia de Alba er idag mere end et bibelværk. Den er også et kulturelt mindesmærke over en periode, hvor tre religioner mødtes i fordragelighed. Med Moses Arragels egne ord lige før begyndelsen af sin oversættelse, (Genesis, kap.1, vers 1): "i al fremtid vil der gå frasagn om denne bog".

Hans egen skæbne i den efterfølgende udrensning melder historien intet om.

Men måske fornemmede han intuitivt Europas skæbnesvangre kurs ind $\mathrm{i}$ årtusindets anden halvdel, mod større traumatiske xenophobier.

BIBLIA DE ALBA. London: FacsimileEditions, 1992.513 tav. + 1 bilag. Companion volume. Ed. by Jeremy Schonfield.

\section{Litteratur:}

The Bible (Old Testament) translated from the Hebrew into Castilian by Rabbi Moses Arragel of Guedalfajara (142233?) and published by The Duke of Berwici and Alba. I-II (The Roxburghe Club Series). Introduction by A. Paz y Mélia, Madrid 1918-21.

Carl-Otto Nordström: The Duke of Alba's Castilian Bible. A Study of the Rabbinical Features of the Miniatures. Uppsala 1967.

S. Fellous: "Une Bibleà la rencontre des cultures," Le Livre au moyen âge, Paris 1989.

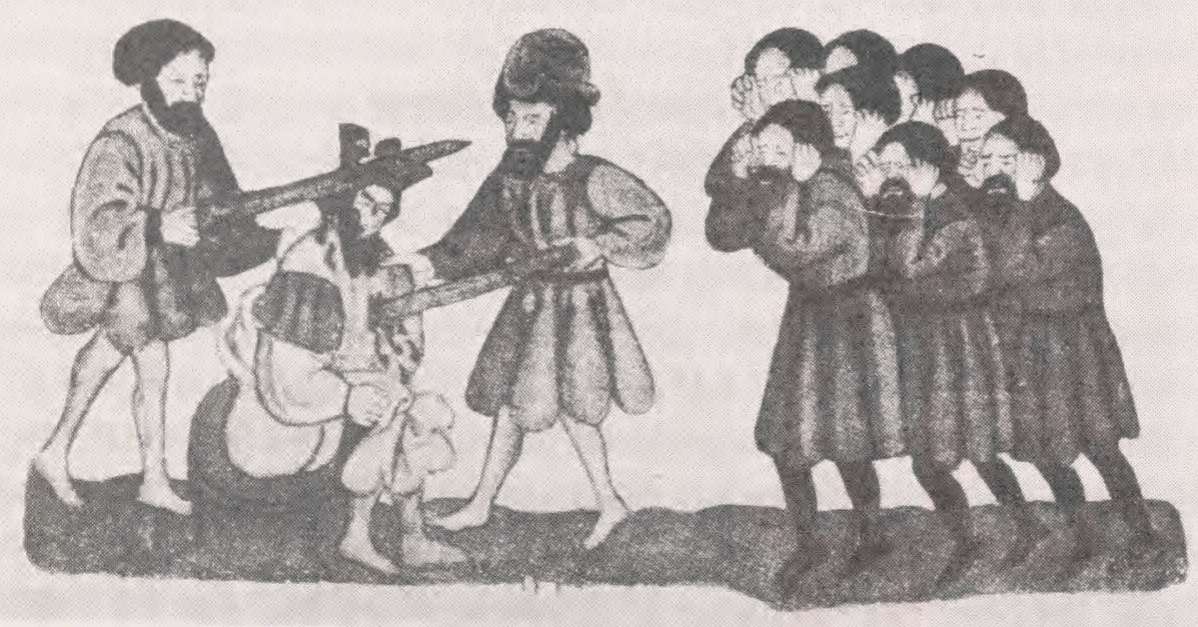

Fol. 464 recto. Belshazzars død (Daniel 5, 30). 